\title{
Using virtual reality learning environments to motivate and socialize undergraduates in distance learning
}

\author{
Murat Çoban \\ Department of Computer Education and Instructional Technology, A ̈̆rı İbrahim Çeçen \\ University, A $\breve{g r l}$, Turkey \\ ORCID: 0000-0003-2415-5747
}

İdris Göksu *

Department of Educational Sciences, Mardin Artuklu University, Mardin, Turkey ORCID: 0000-0002-7120-6562

\begin{tabular}{|c|c|}
\hline Article history & Interest in virtual reality technologies has increased significantly in \\
\hline $\begin{array}{l}\text { Received: } \\
08.04 .2021\end{array}$ & $\begin{array}{l}\text { recent years, and an effort is being made to integrate it into educational } \\
\text { environments. This study aims to investigate the impact of synchronous }\end{array}$ \\
\hline $\begin{array}{l}\text { Received in revised form: } \\
23.06 .2021\end{array}$ & $\begin{array}{l}\text { distance courses in the Virtual Reality (VR) learning environment (via } \\
\text { vAcademia) and Web-based (via Adobe Connect) learning environment } \\
\text { on undergraduate students' learning motivation and levels of perceived }\end{array}$ \\
\hline $\begin{array}{l}\text { Accepted: } \\
15.07 .2021\end{array}$ & $\begin{array}{l}\text { sociability. The sample of the study was conducted with experimental } \\
\text { (VR) and control group (Web-based) quasi-experimental design consists }\end{array}$ \\
\hline Key words: & of 41 undergraduate students (experimental: 21 , control: 20 ). As a result \\
\hline $\begin{array}{l}\text { Virtual reality; } \\
\text { Distance learning; } \\
\text { Higher education; } \\
\text { Motivation; } \\
\text { Socializing }\end{array}$ & $\begin{array}{l}\text { of the t-test and two-way ANOVA analysis, there was a significant } \\
\text { difference between the groups in favor of the VR group regarding } \\
\text { motivation and perceived sociability. The motivation and perceived } \\
\text { sociability in the 3D VR environment of the students in distance learning } \\
\text { were significantly higher than in the web-based environment. It was also } \\
\text { found out that students' motivation and perceived sociability levels did } \\
\text { not vary depending on gender or on the technological device (smartphone } \\
\text { or computer) that students use when connecting to online classes. The } \\
\text { research results indicated that the VR learning environment effectively } \\
\text { ensured students' motivation and sociability in the distance learning } \\
\text { process. In this context, institutions should be aware of the importance } \\
\text { of VR technologies and plan to teach accordingly which may make the } \\
\text { process more efficient. }\end{array}$ \\
\hline
\end{tabular}

\section{Introduction}

The trend towards open and distance learning in the world shows a rapid increase. The development of the Internet and digital technologies and the rising cost of tuition may play an active role in the growth of this trend (Brown et al., 2020). Besides, distance education removes time and space limitations (Liu, 2012), and the content offered in distance education systems is

\footnotetext{
* Correspondency: idrisgoksu@artuklu.edu.tr
} 
mobile compatible (Arthur-Nyarko et al., 2020), making learning more efficient. Since, according to the World Economic Forum, global education technology investments and the distance education market will hit 350 billion dollars by 2025 , up from 18.66 billion dollars in 2019 (Li \& Lalani, 2020). Also, the assumption that distance education will have a global market of approximately 227 billion dollars in 2027 (Research and Markets, 2020) can be considered an indicator of distance education entering our lives more comprehensively (Milićević et al., 2021). Furthermore, many institutions worldwide implement this form of education (Yao et al., 2021).

To this end, besides many educational institutions, higher education institutions should use new technologies in the distance education process to create more effective learning environments (Alsabawy et al., 2016; Saxena, 2021). Noting the importance of this issue, Brown et al. (2020) argue that universities should be ready to teach online. Hence, the Covid-19 pandemic, which emerged globally in 2020, caused many educational institutions to suspend face-to-face education as well as in higher education. As a result of this pandemic, higher education institutions focused more on distance education and increased their efforts to create suitable online learning environments. However, for this effort to be successful, the effectiveness and limitations of the technologies or learning mode (such as asynchronous, synchronous, or hybrid; web-based or VR-based) to be used in the distance education process must be researched well enough (Hrastinski, 2008b). Primarily, choosing environments that enable students to socialize and increase their motivation can provide a more effective learning process.

Sociability is an essential factor that affects collaboration and learning performance between groups (Kreijns et al., 2007), which is necessary to have social skills. Sociability activities in digital environments increase students' level of social space and strengthen their collaborative interactions (Jiang \& Zhang, 2020). Sociability in these environments can be explained by an interest in helping or chatting with others in the relevant setting (Yee, 2006). This interest and desire should not be blocked in this context because when students feel that their social interactions are blocked, their motivation may decrease (Rovai et al., 2007). Low motivation plays an important role in students' online interactions (Xie \& Ke, 2011), which also negatively affects participation in learning activities (Zhou et al., 2011). This situation may also negatively impact students' learning performance since it is argued that when students are motivated, they are more willing to learn and continue to learn (Deimann \& Bastiaens, 2010).

The studies focusing on motivation and sociability in the field of distance education in the literature are quite limited until a few years ago (Bozkurt et al., 2015). However, the fact that there has been a significant increase in research focusing on motivation in recent years shows that questions need to be answered in this regard (Meşe \& Sevilen, 2021). In addition, teachers should make an effort to increase students' motivation in online learning environments (Xie \& $\mathrm{Ke}, 2011)$ and choose the most suitable learning environment in terms of motivation. In this context, it is crucial to examine synchronous learning environments used in distance education (Hrastinski et al., 2010) or have the potential to be used and reveal their effects on motivation and sociability.

\section{Asynchronous and synchronous learning}

Synchronous, asynchronous, or hybrid (at times synchronously or asynchronously) learning methods are generally used in distance education. Asynchronous learning has been among the most preferred distance education methods until recently (Sindiani et al., 2020). Asynchronous education can be provided with teaching management systems (e.g., Moodle, 
Blackboard, Edmodo, various LMSs) or similar systems developed by educational institutions. In virtual classrooms created in such systems, activities such as content sharing (video, presentation, lecture notes, and others), announcements, homework, quizzes, and messaging can be performed. Although asynchronous learning has some advantages over synchronous learning, it may not be sufficient, especially in terms of sociability and motivation (Göksu et al., 2021; Khan, 2011). This learning method is generally insufficient in terms of sociability in the asynchronous learning process, as real-time social interaction between participants is impossible (De Lucia et al., 2009). In addition, with the development of Internet bandwidth and web technologies, many educational institutions have turned to synchronous learning.

Synchronous learning takes place with the participation of the instructor and students in the virtual classroom at a specified time. In addition to voice, camera, and lecture note sharing, instant messaging is also possible in the virtual classroom. Studies show that synchronous learning performed in virtual classrooms reduces loneliness and increases motivation (Hrastinski, 2008a). Furthermore, synchronous distance education makes it easier for students to ask questions, enables direct exchange (Stein et al., 2007; Perbandt et al., 2021), and provides instant feedback. However, since students have less time in synchronous discussions, the rate of meaningfully responding to comments may be lower than asynchronous (Stein et al., 2007; Calderon \& Sood, 2020). The reason is that having flexible working times in distance education is liked by students (Lall \& Singh, 2020).

For this reason, communication in synchronous lessons can only be useful in small groups (Hrastinski et al., 2010). On the other hand, Carr (2000) suggests that distance education causes a lack of social interaction and face-to-face interaction. Therefore, there are still unresolved problems in distance education programs carried out with both modes (Bray et al., 2008), and there is a need to support distance learning with alternative methods. One of these methods is Virtual Reality (VR) learning environments, which are among the most common technologies (Brown et al., 2020) with their immersion feature.

\section{The virtual reality learning environment}

The definition of VR is that the virtual world completely immerses a user without seeing the real world (Carmigniani et al., 2011). Inoue (2012) defines VR (also known as artificial reality, virtual worlds, or cyberspace) as follows: "an interactive computer-based application that provides a synthetic digital environment - and thus, virtual reality provides a way to simulate environments, objects, actions, and processes.". VR has features such as creating virtual environments, multi-channel user interaction, the immersion of the user, intuitive interaction through natural manipulations shows that it can be used pedagogically (Mikropoulos \& Bellou, 2006).

Many educational institutions use VR environments for various purposes viz. distance learning, presentations, meeting, and alike (Minocha \& Reeves, 2010). In addition, many universities have VR projects and research the VR labs they have established (Brown et al., 2020). Therefore, it is recommended to use VR in many educational levels (e.g., K12 and higher education - Merchant et al., 2014) and many educational areas (Chang et al., 2020; Huang et al., 2016). For example, in some studies, it is argued that higher education students are prone to research and learning in VR environments (Zhou et al., 2011) and that VR can narrow the gap between theory and practice in higher education (Dubovi et al., 2017). In addition, VR is increasingly used in business life and educational institutions (Howard \& Gutworth, 2020).

3D VR environments (virtual worlds) have some features not available in the real world (e.g., 
not dying, flying, not being tired, taking on different characters, no physical limitations). In these environments, areas that provide avatar-based social interaction, navigation in 3D spaces, and simultaneous communication can be designed (design spaces). Users are represented in VR environments by avatars, digital assets of unique identity, and human type. Users are usually found in virtual environments through the eyes of their avatars (Howard \& Gutworth, 2020) and can be positioned in any environment they want with the teleport process. In addition, they can communicate using avatars' body language (Pojanapunya \& Jaroenkitboworn, 2011) and perform activities (Ketelhut et al., 2010). Thus, VR environments are more useful than other two-dimensional learning environments (Dalgarno \& Lee, 2010). Besides, VR environments can be used in distance education (Holmberg \& Huvila, 2008). In this study, the 3D VR learning environment ( $v$ Academia) was preferred for the experimental group in synchronous lessons, and a Web-based Adobe Connect environment was selected for the control group.

\section{Sociability and motivation in VR learning environments}

According to Salmon (2004), digital sociability has three components: "establishing a successful group," "knowledge domain," and "online environment." All these three components are present in VR learning environments. Dalgarno and Lee (2010) state that 3D VR environments contribute to spatial knowledge by experiencing motivation, engagement, contextual learning, and cooperative learning. Students find this environment suitable for socializing (Liou, 2012), and they can interact with others while performing some tasks in these environments (Huang et al., 2016). Voice communication offered by VR environments (via Virtual Worlds) may also affect this interaction because voice communication strongly affects students' emotional and learning performance (Yamada, 2009). Such VR environments provide a safe environment for users to practice and develop their social skills without feeling shy (Howard \& Gutworth, 2020). As the users' sociability perception increases, the trust in the environment, the perceived sociability, and satisfaction levels increase (Hassanein \& Head, 2004). As a result, the sociability problem felt in distance education can be eliminated.

Similarly, Edirisingha et al. (2009) determined that VR (via Second Life) contributes to the sociability of distance learners. In a recent meta-analysis, 23 studies were examined, and it was found that non-immersive or non-gamified VR yielded better results (Howard \& Gutworth, 2020). The vAcademia platform used in this study has a non-immersive feature, and the designed lessons are not gamified.

VR environments are effective environments in terms of motivation. Users generally find these environments exciting and entertaining (Liou, 2012). In addition, as they use VR environments, they can develop digital experiences and thus be motivated to achieve their goals (Howard \& Gutworth, 2020). In VR learning environments, users can learn and become motivated by having fun (Chang et al., 2020; Holmberg \& Huvila, 2008; Yilmaz et al., 2016). The increase in students' motivation ensures their engagement in learning activities (Merchant et al., 2014). Also, Ketelhut et al. (2010) emphasized that students can do research in VR environments, and thus, they are motivated. VR learning environments especially increase students' intrinsic motivation (Tüzün et al., 2009).

Students' sociability in VR environments (e.g., Virtual Worlds) supports their motivation (Zhou et al., 2011). In addition, factors such as social relationships, interaction, gaming, and sociability help evoke motivation (Liu et al., 2011). Therefore, the immersive or non-immersive nature of VR environments may not reduce its impact on motivation. It was similarly suggested that there is no significant difference between immersive displays (e.g., $C A V E$ ) and the monitor 
in terms of motivation (Howard \& Gutworth, 2020). On the other hand, studies indicate that students may lose their motivation to learn in VR environments (Cuperus et al., 2018).

It is emphasized that the gender factor is also an important variable in distance learning motivation and socialization (Lee, 2002). For example, while males traditionally have higher technology proficiency (Yawson \& Yamoah, 2021), females are more likely to express their emotions and socialize in online forums or other communication platforms than males (Zhang et al., 2013). These differences can contribute to the distance learning process. However, the gender factor among students in distance education is rarely discussed (Tang et al., 2021). It may also be critical which devices students choose when connecting to distance learning environments because the different features of devices such as mobile, desktop, or notebook may affect the engagement and satisfaction of students (Mockus et al., 2011; Ploj Virtic et al., 2021). For example, in a recent study conducted during the Covid-19 pandemic (Göksu et al., 2021), the attendance and distance learning motivation of those who prefer computers in distance education courses are higher than those who prefer smartphones. In addition, the related research determined that female students participated in the classes more than males, but males' motivation was higher. Therefore, this study is important to obtain new evidence regarding motivation and socialization according to gender and preferred device.

It is emphasized that variables such as students' perception of sociability in the online learning environment, motivation level, adaptation process to the environment, and perception of social welfare affect attendance and learning performance (Bardakçı, 2010). Therefore, it is essential to determine the sociability perceptions of distance learners who experience the VR learning environment in this context. Howard and Gutworth (2020) also underlined the need for experimental studies to reveal the effects of these environments on sociability and social skills. In this direction, this study aims to investigate vAcademia, defined as a 3D VR learning environment, and Adobe Connect environment, which is used as a web-based synchronous course platform, in the context of motivation and perceived sociability variables. For this purpose, research questions are formulated as follows:

Between 3D VR-based synchronous course and web-based synchronous course,

(1) Is there a significant difference in terms of perceived sociability?

(2) Is there a significant difference in terms of distance learning motivation?

(3) Does the perceived sociability and distance learning motivation differ by gender?

(4) Does the perceived sociability and distance learning motivation differ by the selected technological device while participating in the distance education environment?

\section{Methodology}

\section{Research design}

In this study, a control group post-test quasi-experimental design, one of the quantitative research methods, was used (McMillan \& Schumacher, 2010). The control group post-test quasi-experimental design is defined as a research design that controls all potential threats for internal validity, as in the quasi-experimental design with the pretest-posttest control group, since it includes a control group and participants are randomly assigned to the groups. However, since the study aims to measure the participants' motivation and sociability in specifically defined educational environments (VR-based synchronous lesson and web-based synchronous 
lesson), a pretest was unnecessary. In addition, the students participating in the research process did not receive any previous training regarding the learning content offered.

\section{Participants}

The research participants included 41 prospective teachers ranging in age from 21-25, including 17 females and 24 males. The prospective teachers are fourth-grade students enrolled in the Computer Education and Instructional Technology department at a university in Turkey. The participants are at the same grade level and have similar academic experiences. They were determined using the purposive sampling method. Students do not have previous VR-based (via Virtual Worlds) synchronous course experience. All of the participants took part in the study voluntarily. Twenty-one participants (Female: 6, Male: 15) constitute the experimental group, and 20 (Female: 11, Male: 9) the control group. The experimental group participated in synchronous lessons in a 3D VR learning environment (via vAcademia) and the control group in a web-based (via Adobe Connect) learning environment.

\section{Learning environments designed in this study}

In this research, vAcademia software was chosen as the VR learning environment (vAcademia, 2020). vAcademia is a 3D virtual world-based education platform developed in the Multimedia System Laboratory environment of Mari State Technical University in Russia (Morozov et al., 2012). The vAcademia platform has similar features with other 3D virtual world platforms. However, this environment includes some extra functions different from the other virtual world platforms.

First of all, it would be crucial to pinpoint herein that vAcademia is an environment specially designed for educational purposes. In this context, the virtual interactive board is equipped with classroom layout templates, permission tools, and interaction tools. vAcademia offers the opportunity to apply both synchronous and asynchronous learning approaches by recording all activities in the 3D environment (movements of avatars, textual and voice chats, used media content, etc.). Thus, students can follow a recorded lecture asynchronously as much as they want. Another feature of this environment can be shown as the opportunity to view the real or avatar-based image of the tutor by other avatars. Hence, it is ensured that the view of the participants in the real environment is integrated with the virtual environment.

Thanks to the classroom control tools offered by the vAcademia platform, students can also use the content contained in the environment and prevent foreign persons present in the environment (Morozov et al., 2012). In addition, the environment's flexible and useful tools can be used to manage the teaching process. For example, advanced presentation tools offered by the vAcademia environment allow you to share documents in the environment and work on them interactively. In addition, it is more flexible and easier to design and develop ready-made educational tools in this environment (Prasolova-Førland et al., 2013). Because of these features, the vAcademia environment was selected as the $3 \mathrm{D}$ virtual world platform in the research.

The Adobe Connect platform was used as another synchronous teaching tool. All students have the experience of using this platform before. Users use various real-time technologies in the Adobe Connect environment, such as video and audio conferencing, chat, screen sharing, and whiteboard. Adobe Connect allows educators to easily create and deliver synchronous courses at their own pace, execute highly interactive virtual classrooms, and effectively manage teaching programs (Adobe Connect, 2020). In addition, Adobe Connect is a distance learning 
software that has recently been recognized in universities and is widely used worldwide (Kaya, 2012). For this reason, Adobe Connect software was preferred for students in the control group to compare it with the vAcademia environment.

\section{Course Design}

The study groups followed the Digital Game Design and Development course with detailed curriculum guidance in Table 1. The researchers prepared the learning contents covering seven weeks. Learning contents were presented by the same tutor (the first author) in both study groups.

Table 1. Course process.

\begin{tabular}{|c|c|c|c|}
\hline \multirow{2}{*}{ Week } & \multirow{2}{*}{ Topics } & \multicolumn{2}{|c|}{ Weekly course time } \\
\hline & & vAcademia & Adobe Connect \\
\hline 1 & Getting to know the Unity 3D game engine and its features & $39 \mathrm{~min}, 40 \mathrm{~s}$ & $37 \mathrm{~min}, 16 \mathrm{~s}$ \\
\hline 2 & $\begin{array}{l}\text { Designing environments and creating objects in the Unity } \\
\text { 3D game engine }\end{array}$ & $41 \mathrm{~min}, 11 \mathrm{~s}$ & $43 \mathrm{~min}, 15 \mathrm{~s}$ \\
\hline 3 & $\begin{array}{l}\text { Adding game characters to the Unity 3D environment } \\
\text { Adding Ragdoll component to characters }\end{array}$ & $47 \mathrm{~min}, 36 \mathrm{~s}$ & $45 \mathrm{~min}, 13 \mathrm{~s}$ \\
\hline 4 & $\begin{array}{l}\text { Animate a character in Unity 3D environment } \\
\text { Adding sound to Unity 3D environment } \\
\text { Unity 3D physics programming components }\end{array}$ & $44 \mathrm{~min}, 11 \mathrm{~s}$ & $45 \mathrm{~min}, 33 \mathrm{~s}$ \\
\hline 5 & $\begin{array}{l}\text { Introduction of Unity 3D programming components } \\
\text { Unity 3D Raycast component and properties }\end{array}$ & $47 \mathrm{~min}, 33 \mathrm{~s}$ & $49 \mathrm{~min}, 39 \mathrm{~s}$ \\
\hline 6 & $\begin{array}{l}\text { Unity 3D programming (Continued) } \\
\text { Adding motivating design elements to a digital game } \\
\text { - Malone's motivation theory and components } \\
\text { - Mihaly Csikszentmihalyi's flow theory and features } \\
\text { - Game-based learning theory and features }\end{array}$ & $51 \mathrm{~min}, 36 \mathrm{~s}$ & $48 \mathrm{~min}, 12 \mathrm{~s}$ \\
\hline 7 & Publishing a project prepared in Unity $3 \mathrm{D}$ environment & $24 \mathrm{~min}, 17 \mathrm{~s}$ & $25 \mathrm{~min}, 14 \mathrm{~s}$ \\
\hline \multicolumn{2}{|c|}{ Total tuition time: } & $4 \mathrm{~h}, 56 \mathrm{~min}, 4 \mathrm{~s}$ & $4 \mathrm{~h}, 54 \mathrm{~min}, 22 \mathrm{~s}$ \\
\hline
\end{tabular}

Before the experimental process, a general introductory document using the vAcademia environment was sent to the students via the distance education platform. In addition, orientation training was given to the students for two weeks to adapt to the vAcademia environment. During the orientation training process, the students experienced the vAcademia environment and discovered the features offered by the environment.

General information about the Unity 3D game engine was given to the study groups in the first week. In addition, in the first week, students were enabled to navigate the vAcademia environment, to recognize and use the tools in the environment (such as chat, drawing, movement in the environment, and turning on the camera). In the remaining weeks, basic information about Unity 3D game engine design, creating 3D objects, adding characters, adding sound, animation, and game programming was presented to students. In addition, students were allowed to follow the educational activities offered on vAcademia and Adobe Connect whenever they want. At the end of the course, the students published their game designs. Figure 1 shows the image of the sample lessons performed in vAcademia and Adobe Connect environments. 

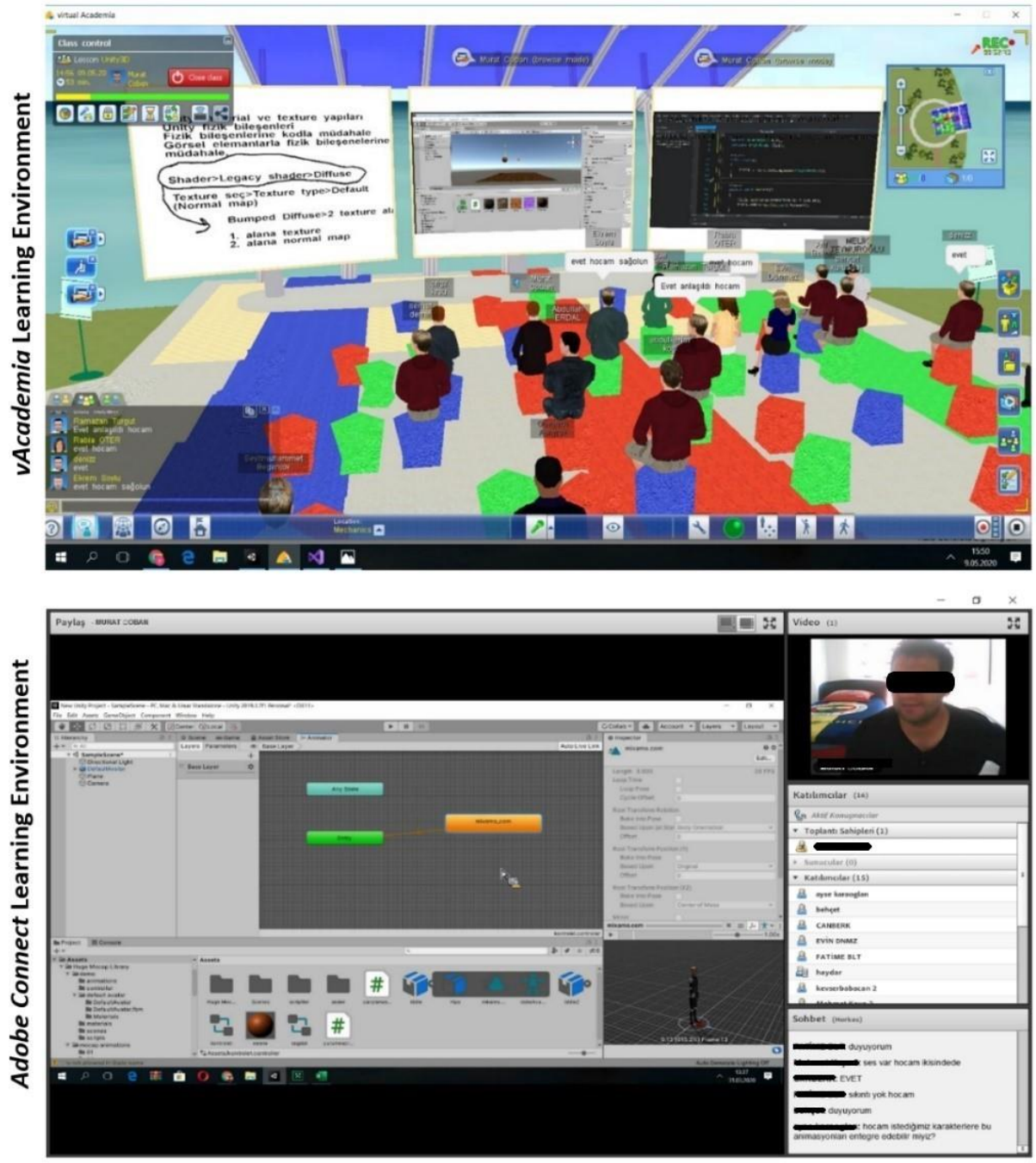

Figure 1. Courses via vAcademia and Adobe Connect

The instructor interacted with the students by using the presentation and interaction tools in both environments. For example, the instructor shared the applications on his computer on a virtual screen in the vAcademia environment, drawing his image on other virtual screens. Besides, students chatted with the instructor and other students by voice and text messages with the help of avatars representing them. Similarly, the instructor interacted with the students using the tools provided by the software during the activities in the Adobe Connect environment. For example, the instructor interacted with the students using whiteboard sharing, chat, screen sharing, and image sharing. In addition, students interacted with each other by using voice and text chat options. At the end of the seven-week process, data was collected from the students via online forms (using Google Forms), and the process was completed.

\section{Measures}

In the study, the Perceived Sociability Scale developed by Kreijns et al. (2007) and adapted into Turkish by Bardakçı (2010) was used to measure the perceived sociability level of the participants $(\alpha=.82)$. The five-point Likert-type scale (1: Strongly disagree, 2: Disagree, 3: Undecided, 4: Agree, 5: Strongly agree), grouped under a single factor, consists of 10 items. The Cronbach Alpha internal consistency coefficient of the scale was determined as $\alpha=.90$ in this study. Accordingly, it can be argued that the scale is quite reliable. 
The Instructional Material Motivation Scale, developed by Keller (2010), adapted into Turkish by Dinçer and Doğanay (2016), and adapted to distance learning by Göksu et al. (2021), was used to measure the motivation level of the participants regarding the learning environment. Göksu et al. (2021) adapted the scale for distance learning to measure university students' distance learning motivation. In addition, they conducted confirmatory factor analysis (total $\alpha$ $=0.97$, attention $\alpha=0.93$, relevance $\alpha=0.91$, confidence $\alpha=0.92$, and satisfaction $\alpha=0.93$ ). The five-point Likert-type scale (1: Strongly disagree, 2: Disagree, 3: Undecided, 4: Agree, 5: Strongly agree) contains a total of 33 items. Furthermore, the scale's Cronbach Alpha internal consistency coefficient was determined as $\alpha=.98$ in this study. Accordingly, it can be suggested that the scale is quite reliable.

\section{Data analysis}

We conducted $t$-test and two-way ANOVA to analyze the research data. For this reason, the data related to the participants' perceived sociability and motivation levels in the study were analyzed using two separate $t$-tests. In addition, two-way ANOVA analysis was used to examine the effect of two independent variables on a dependent variable.

First of all, whether the data meet the assumptions of the t-test and two-way ANOVA was tested. Since the sample size was $\mathrm{n}<50$, the Shapiro-Wilk was used as normality test, in this context, the perceived sociability variable was found to be $p=.074$ for students in the $v$ Academia group and $p=.013$ for students in the Adobe Connect group. The Shapiro-Wilk test results of the motivation variable were $p=.015$ for students in the $v$ Academia group and $p=$ .236 for students in the Adobe Connect group. As a result of the normality test performed for the vAcademia group, kurtosis (-0.920) and skewness (0.230) values for the sociability variable showed that the data were distributed normally. Besides, kurtosis (-0.932) and skewness $(0.118)$ values calculated for the motivation variable were found to meet the normality assumption. As a result of the normality test for the Adobe Connect group, kurtosis (-1.404) and skewness (2.308) values for the sociability variable showed that the data were distributed normally. Additionally, kurtosis (-0.734) and skewness (-0.106) values calculated for the motivation variable were found to meet the normality assumption (Haire et al., 2013). Also, Levene's Test For Equality of Variances test was used to test the homogeneity of variances. According to the results of this test, it was found out that the variances regarding sociability and motivation variables for both groups were homogeneous $(p>.05)$.

\section{Results}

\section{Perceived sociability}

$W e$ conducted $t$-test to determine whether there was a difference in perceived sociability among the study groups. The results are presented in Table 2.

Table 2. Comparison of the groups in terms of perceived sociability.

\begin{tabular}{llllllll}
\hline \multirow{2}{*}{ Variable } & \multicolumn{2}{l}{ vAcademia } & \multicolumn{2}{l}{ Adobe Connect } & \multirow{2}{*}{$F$} & \multirow{2}{*}{ t(41) } & \\
\cline { 2 - 7 } & $M$ & $S D$ & $M$ & $S D$ & & \\
\hline Perceived Sociability & 3.95 & .63 & 3.35 & .84 & .689 & 2.616 & .013 \\
\hline
\end{tabular}

When Table 2 is examined, it is seen that there is a difference in favor of the vAcademia group in terms of perceived sociability among the study groups. In this respect, it was found that the average value of the students in the vAcademia group regarding the perceived sociability variable was higher than the students in the Adobe Connect group. $t$-test analysis results were 
used to test whether the difference was significant or not. According to the $t$-test results presented in Table 2, a significant difference was observed between the groups $\left[\mathrm{t}_{41}=2.616, p\right.$ $<.05, \mu^{2}=0.149$ ]. In addition, the difference was found to be very large according to the effect size value, which is an indicator of the level of difference between groups $\left[\mu^{2}=0.149>0.138\right]$.

\section{Distance learning motivation}

The results of the $t$-test analysis conducted to determine whether there is a difference in distance learning motivation among the study groups are presented in Table 3.

Table 3. Comparison of the groups in terms of learning motivation.

\begin{tabular}{llllllll}
\hline \multirow{2}{*}{ Variable } & \multicolumn{2}{l}{ vAcademia } & \multicolumn{3}{c}{ Adobe Connect } & \multirow{2}{*}{ t(41) } & $p$ \\
\cline { 2 - 7 } & $M$ & $S D$ & $M$ & $S D$ & & & \\
\hline Motivation & 3.74 & .84 & 3.17 & .84 & .040 & 2.142 & .039 \\
\hline
\end{tabular}

When Table 3 is examined, it is seen that the average of the students in the vAcademia group regarding the motivation variable is higher than the students in the Adobe Connect group. $t$-test analysis results were used to test whether the difference was significant or not. According to the $t$-test results presented in Table 3, a significant difference was observed between the groups $\left[\mathrm{t}_{(41)}=2.142, p<.05, \mu^{2}=0.105\right]$. It was also determined that the difference according to the effect size value was huge $\left[\mu^{2}=0.105>0.138\right]$.

\section{Sociability and distance learning motivation by gender}

Two-way ANOVA analysis was conducted to determine whether the participants' sociability and distance learning motivation variables differ by gender. The results are presented in Table 4.

Table 4. Sociability and distance learning motivation results by gender.

\begin{tabular}{|c|c|c|c|c|c|c|}
\hline Perceived sociability & SS & $d f$ & Mean Square & $F$ & $p$ & $\mu^{2}$ \\
\hline Corrected Model & $4.158^{\mathrm{a}}$ & 3 & 1.38 & 2.42 & .081 & .164 \\
\hline Intercept & 498.71 & 1 & 498.71 & 872.87 & .000 & .959 \\
\hline Gender & .27 & 1 & .27 & .47 & .495 & .013 \\
\hline GroupName & 4.15 & 1 & 4.15 & 7.27 & .010 & .164 \\
\hline Error & 21.14 & 37 & .57 & & & \\
\hline $\begin{array}{l}\text { Distance } \\
\text { motivation }\end{array}$ & & & & & & \\
\hline Corrected Model & $4.98^{\mathrm{b}}$ & 3 & 1.66 & 2.33 & .090 & .159 \\
\hline Intercept & 445.70 & 1 & 445.70 & 626.64 & .000 & .944 \\
\hline Gender & .66 & 1 & .66 & .93 & .341 & .025 \\
\hline GroupName & 2.75 & 1 & 2.75 & 3.87 & .056 & .095 \\
\hline Error & 26.31 & 37 & .71 & & & \\
\hline
\end{tabular}

When Table 4 is examined, it is seen that the $p$-value of the gender for the perceived sociability variable is greater than $.05\left[F_{(1,37)}=.47, p=.495\right]$. In addition, it was determined that the $p$ value for distance learning motivation is greater than $.05\left[F_{(1,37)}=.93, p=.341\right]$. These results show that the participants' perceived sociability and distance learning motivation levels do not differ by gender. 


\section{Sociability and distance learning motivation by the selected technological device}

Two-way ANOVA analysis was used to determine whether the participants' sociability and distance learning motivation differ by the technological device they selected while participating in synchronous learning environments. The results are presented in Table 5.

Table 5. Sociability and distance learning motivation by the technological device.

\begin{tabular}{lllllll}
\hline Perceived sociability & SS & $d f$ & Mean Square & $F$ & $p$ & $\mu 2$ \\
\hline Corrected Model & $4.47^{\mathrm{a}}$ & 3 & 1.49 & 2.65 & .063 & .177 \\
Intercept & 258.56 & 1 & 258.56 & 459.48 & .000 & .925 \\
GroupName & .63 & 1 & .63 & 1.12 & .296 & .030 \\
Device (computer/smartphone) & .40 & 1 & .40 & .72 &. $\mathbf{4 0 0}$ & .019 \\
Error & 20.82 & 37 & .56 & & & \\
\hline Distance learning motivation & & & & & & .129 \\
\hline Corrected Model & $4.38^{\mathrm{b}}$ & 3 & 1.46 & 2.00 & .140 \\
Intercept & 226.33 & 1 & 226.33 & 311.11 & .000 & .894 \\
Device (computer/smartphone) & .33 & 1 & .33 &. $\mathbf{4 5}$ & $\mathbf{. 5 0 3}$ & .012 \\
GroupName & .78 & 1 & .78 & 1.08 & .304 & .028 \\
Error & 26.91 & 37 & .72 & & & \\
\hline
\end{tabular}

Note. ${ }^{\mathrm{a}}: R^{2}=.177$ (Adj. $R^{2}=.110$ ) for perceived sociability, ${ }^{\mathrm{b}}: R^{2}=.140\left(\right.$ Adj. $\left.R^{2}=.070\right)$ for distance learning motivation, SS: Sum of scores

When Table 5 is examined, it is seen that the $p$-value for the perceived sociability variable for the device was greater than $.05\left[F_{(1,37)}=.72, p=.400\right]$. It was also determined that the $p$-value for distance learning motivation is greater than $.05\left[F_{(1,37)}=.45, p=.503\right]$. In this context, attendance of the participants to synchronous lessons with computers or smartphones does not make any difference in perceived sociability and distance learning motivation levels.

\section{Discussion and conclusion}

In this study, where we compare 3D VR-based and web-based distance learning environments, we aimed to determine whether there is a difference in distance learning motivation and sociability variables. Moreover, we attempted to reveal whether these variables differ according to the devices (via computer or tablet) and gender of undergraduate students who are distance learning. We analyzed the quantitative data we obtained in this study, which we conducted with a semi-experimental design, by the $t$-test and two-way ANOVA. Finally, we made suggestions to higher education institutions, VR developers, and practitioners by discussing the results we obtained in line with the literature.

Firstly, the motivation of distance learning students in the 3D VR environment was significantly higher than the web-based environment. Learning by having fun in the 3D VR environment can be an essential factor in increasing motivation. Based on this fact, many studies in the literature draw attention to the entertaining and motivating features of 3D VR environments (e.g., Chang et al., 2020; Dalgarno \& Lee, 2010; Holmberg \& Huvila, 2008; Liou, 2012; Yilmaz et al., 2016; Hrastinski, 2008a; Cho \& Lim, 2017). Howard and Gutworth (2020) argue that students comprehend digital experiences and become motivated to use such environments. High motivation in the VR learning environment may be because the relevant setting is suitable for research (Ketelhut et al., 2010). In addition, the fact that this environment is more suitable for interaction may have increased motivation because the interaction is a factor that helps evoke motivation (Liu et al., 2011). The motivation of the students may also have made the interaction stronger. On this topic, Xie and Ke (2011) suggested that motivation plays an important role in 
online interaction, and participation in classes may be negatively affected if motivation decreases. When students are motivated, they are more willing to learn (Deimann \& Bastiaens, 2010), and they are more engaged (Merchant et al., 2014).

On the other hand, students' motivation level may also be due to the novelty effect of the VR environment. Rogers (2003) emphasizes that innovation is important in individuals' adoption and speed of adoption. Davis (1989) argued that individuals' internal decision-making processes are more effective in adopting innovation. Therefore, the process of adopting innovations, on the one hand, with the innovation itself; On the other hand, it is understood that innovation is a multivariate and complex process related to the system and individuals in which it is used (Usluel \& Mazman, 2010). For this reason, it should be considered that the motivation process of the participants may also be affected by this complex process.

Studies have shown that synchronous learning decreases loneliness and increases motivation (Hrastinski, 2008a). Thus, both learning environments used in this study are suitable for synchronous learning. However, the motivation was significantly higher in the 3D VR environment, indicating that this environment may be more effective in reducing loneliness. Also, it is noteworthy that the environment has increased distance learning motivation, although it does not have an immersive feature. This finding supports the results of Howard and Gutworth's (2020) meta-analysis, which asserted that the immersive or non-immersive VR environment does not make a difference in terms of motivation.

Instructors need to choose the most appropriate environment to increase students' motivation in distance education. In this study, synchronous lessons in a 3D VR environment were more effective than web-based lessons in terms of motivation. Ozonur et al. (2018), applying a similar method to our study, compared 3D VR (via Second Life) and web-based (via Adobe Connect) as a distance learning environment and found a significant difference in favor of VR at the motivation level. Also, in the relevant study, the group's motivation that received training with Adobe Connect decreased. Motivation certainly may not just have its sources in the nature of the environment. In addition to the environment's characteristics, the instructor's attitude, the way of presenting the lesson, and communication can also be effective. However, the fact that the experimental research process was applied in both the relevant study and this study and similar results were achieved make the effect of $3 \mathrm{D}$ VR on motivation strong.

Secondly, the sociability levels of the students who attended the distance education lessons in the 3D VR environment were significantly higher than the web-based environment. This result may be because 3D VR learning environments allow students to communicate more quickly and are more suitable for social interaction. Studies have shown that $3 \mathrm{D}$ VR is suitable for sociability (Liou, 2012); it allows students to practice their social skills without feeling shy (Howard \& Gutworth, 2020) and enables them to interact with each other while performing tasks continues (Huang et al., 2016). Therefore, these possibilities offered by 3D VR may not have been fully formed in web-based synchronous lessons (Huang et al., 2016; Cho \& Lim, 2017). For example, Yilmaz et al. (2016) compared 3D VR (via Second Life) with Adobe Connect. They found out that 3D VR significantly increased students' social presence and that students communicated with each other more easily. Ozonur et al. (2018) similarly revealed that the VR environment is more effective.

One of the most critical features of synchronous lessons in distance education is that it provides audio communication. This feature has a significant effect on students' emotional and learning performance (Yamada, 2009). Both learning environments that we examined in this study 
provide opportunities for audio communication. However, in the web-based Adobe Connect environment, while the audio communication is mainly under the instructor's control, in the 3D VR environment, students can communicate with each other independently from the instructor. This advantage of the 3D VR learning environment may have made the sociability process more active. In this way, students' collaborative interactions may have strengthened, and their level of social presence increased (Jiang \& Zhang, 2020), and thus a more favorable sociability environment may have been created. Students' perception of sociability regarding the learning environment also increases their satisfaction with the environment (Hassanein \& Head, 2004), minimizing social sociability and loneliness experienced in distance education. The result we obtained in this study strengthens the claim that VR is suitable for the sociability of distance learners (Edirisingha et al., 2009) and reveals that it is more effective than web-based synchronous lessons. A recent meta-analysis determined that VR gives better results in this context (Howard \& Gutworth, 2020). The relevant meta-analysis concluded that 3D VR learning environments are more effective if they are not immersive and not gamified. The fact that the VR environment we preferred in this study has similar properties confirms the relevant results. Additionally, immersive VR environments with immersive features (e.g., headmounted displays) are costly, fragile, and not very suitable for long-term use (Huang et al., 2016), making the results we have determined regarding the $3 \mathrm{D}$ VR environments we researched more valuable.

It is suggested that communication in distance learning environments can only be efficient with small groups (Hrastinski et al., 2010). The fact that the groups consisted of an ideal number of students in this study shows that a favorable environment for communication was formed. If the groups were crowded, it was likely that the appropriate communication environment would not be created. Therefore, our results in the context of sociability could also remain weak.

Synchronous lessons often provide students with the opportunity of asking questions more comfortably (Stein et al., 2007; Perbandt et al., 2021) and enable instant feedback to questions. However, since students have less time in synchronous discussions, the rate of responding to the comments may be low (Stein et al., 2007). Therefore, we did not focus on variables like asking questions and feedback in this study. However, in this regard, it is also thought that the 3D VR environment is more favorable. Considering that such variables may affect motivation and the 3D VR environment was more effective in terms of motivation, this study supports this idea. Nevertheless, some studies suggest that students' sociability in VR environments also contributes to their motivation (Zhou et al., 2011).

Thirdly, distance learning students' motivations and sociability did not differ by gender. The fact that the 3D VR environment offers students the opportunity to express themselves comfortably and with different identities (via avatar) may be one reason why there is no difference in terms of motivation and sociability variables according to gender. Cho et al. (2015) found that gender does not affect social presence. On the other hand, some studies found that the effect of VR in the context of trust is higher in women (Ausburn \& Ausburn, 2008) and that women spend more time communicating and socializing with others in VR environments (Guadagno et al., 2011). Also, according to Zhou et al. (2011), women mostly focus on activities that increase sociability, such as research, exploring, and shopping in $3 \mathrm{D}$ VR environments, while men generally focus on making money. Although these results in the literature indicate that there may be a difference in behaviors according to gender, they do not give us an exact result in terms of sociability. Our study determined that the distance learning motivation and sociability levels of the students who experienced the 3D VR environment and web-based distance course learning environment did not differ by gender. This result shows 
there is no need for different applications that increase motivation or sociability specific to men or women in synchronous lessons (via 3D VR or web-based).

Lastly, the devices selected by students while attending distance learning classes also did not create any difference in the motivation for sociability and distance learning. In this study, students chose to take synchronous distance courses either by computer or tablet. The research results pinpointed that participating in distance synchronous lessons using a computer or tablet does not differ regarding the level of motivation or sociability. It was expected that the tablet would be more portable, convenient, and accessible than the computer, making a difference in the measured variables. Mobile devices are more helpful in attending classes anywhere at any time. There were no differences that may have been caused by the period when we conducted experimental research. In the relevant period, universities stopped their face-to-face education and started distance education due to the Covid-19 pandemic. Therefore, the curfews also required undergraduate students to attend synchronous lessons from home continuously. Thus, the mobile feature of the mobile device may not have much meaning at that time. This situation may have caused the motivation and sociability variables not to differ according to the selected device. Therefore, it can be said that different studies should further confirm this result.

The study results, in this regard, showed that 3D VR in higher education makes significant contributions in terms of motivation and sociability in synchronous distance courses. In the current period, it can be suggested that educators have adopted a digital learning approach and that their perception of teaching technologies has changed in a positive sense every day. Therefore, higher education institutions should be ready to teach online (Brown et al., 2020). In this context, institutions know the most effective learning environments (Hrastinski, 2008b) and plan to teach accordingly will make the process more efficient. From this point of view, this research has contributed important evidence to the literature.

\section{Limitations and suggestions}

We believe that this study has some limitations that should be considered in future research. 3D VR learning environments can have high potential in the context of both sociability and learning motivation. However, it should be noted that VR cannot yet offer completely realistic environments (Howard \& Gutworth, 2020). Therefore, the importance of VR developers to design more realistic VR environments can increase the effectiveness of related environments. It is regarded as important that these environments are realistic and allow interaction and communication (Yilmaz et al., 2016). In addition, the need to recognize people who live, breathe, and learn behind avatars in 3D VR environments reveals that the responsibilities of tutors and learners should be taken into account (Salmon, 2009). Having users in virtual environments through avatars' eyes can also cause them to feel connected with their avatars (Howard \& Gutworth, 2020). These features of VR environments can enable students to experience a strong sense of presence (Edirisingha et al., 2009). In the 3D VR environment, it is also crucial for students to express their emotions along with social connections in their satisfaction (Bulu, 2012). In this context, new researches can enable educators to get to know 3D VR environments better.

The inclusion of 3D VR learning environments in distance education programs by higher education institutions can improve learning motivation and sociability. In addition, it can narrow the gap between theory and practice (Dubovi et al., 2017). It is known that many studies have been conducted on the effectiveness of VR in higher education, and it contributes significantly to the context of social presence, interaction, communication, sociability, and 
motivation. Therefore, conducting new research using the method we followed in this study and comparing various learning environments experimentally (not with the traditional classroom environment) may contribute to the literature.

In this study, we compared 3D VR with a web-based environment. We focused on distance learning motivation and sociability variables. However, we did not aim to determine learning objectives. Therefore, it can be investigated whether 3D VR-based or web-based synchronous lessons are more effective in academic achievement. Finally, this study was carried out with undergraduate students. However, it is thought that such researches need to be done in K12 too.

Studying 3D VR learning environments in terms of various variables can yield significant results. Besides, further research to improve sociability, motivation, academic achievement, or engagement in web-based environments is necessary. The reason is that currently, the vast majority of distance education programs prefer web-based systems, and it is assumed that these systems will be needed for a long time in the future.

Consequently, although users are represented by avatars in 3D VR environments and can establish eye contact, they may be concerned about the "face" (Pojanapunya \& Jaroenkitboworn, 2011). Therefore, in the future, if VR developers integrate an individual's real face into the avatar, the effectiveness and usefulness of the relevant environments may increase multiple times.

\section{References}

Adobe Connect. (2020, July 10). Adobe Connect for e-Learning. http://www.adobe.com/products/adobeconnect/elearning.html

Alsabawy, A. Y., Cater-Steel, A., \& Soar, J. (2016). Determinants of perceived usefulness of e-learning systems. Computers in Human Behavior, 64, 843-858. https://doi.org/10.1016/j.chb.2016.07.065

Arthur-Nyarko, E., Agyei, D. D., \& Armah, J. K. (2020). Digitizing distance learning materials: Measuring students' readiness and intended challenges. Education and Information Technologies, 25, 2987-3002. https://doi.org/10.1007/s10639-019-10060-y

Ausburn, L. J., \& Ausburn, F. B. (2008). Effects of desktop virtual reality on learner performance and confidence in environment mastery: Opening a line of inquiry. Journal of STEM Teacher Education, 45(1), 54-87.

Bardakç1, S. (2010). The validity and reliability study of the scale of the perceived sociability of online learning environments. Ankara University Journal of Faculty of Educational Sciences, 43(1), 17-39.

Bozkurt, A., Akgun-Ozbek, E., Yilmazel, S., Erdogdu, E., Ucar, H., Guler, E., ... Aydin, C. H. (2015). Trends in distance education research: A content analysis of journals 20092013. International Review of Research in Open and Distance Learning, 16(1), 330363. https://doi.org/10.19173/irrodl.v16i1.1953

Bray, E., Aoki, K., \& Dlugosh, L. (2008). Predictors of learning satisfaction in Japanese online distance learners. International Review of Research in Open and Distance Learning, 9(3). https://doi.org/10.19173/irrodl.v9i3.525

Brown, M., McCormack, M., Reeves, J., Brooks, D. C., Grajek, S., Alexander, B., ... Weber, N. (2020, July 17). 2020 EDUCAUSE Horizon Report: Teaching and Learning Edition. https://library.educause.edu/-/media/files/library/2020/3/2020_horizon_report_pdf.pdf 
Bulu, S. T. (2012). Place presence, social presence, co-presence, and satisfaction in virtual worlds. Computers and Education, 58(1), 154-161. https://doi.org/10.1016/j.compedu.2011.08.024

Calderon, O., \& Sood, C. (2020). Evaluating learning outcomes of an asynchronous online discussion assignment: a post-priori content analysis. Interactive Learning Environments, 28(1), 3-17. https://doi.org/10.1080/10494820.2018.1510421

Carmigniani, J., Furht, B., Anisetti, M., Ceravolo, P., Damiani, E., \& Ivkovic, M. (2011). Augmented reality technologies, systems and applications. Multimedia Tools and Applications, 51(1), 341-377. https://doi.org/10.1007/s11042-010-0660-6

Carr, S. (2000). As distance education comes of age, the challenge is keeping the students. Chronicle of Higher Education, 46(23), 39-41.

Chang, S., Hsu, T., Kuo, W., \& Jong, M. S. (2020). Effects of applying a VR-based two-tier test strategy to promote elementary students' learning performance in a Geology class. British Journal of Educational Technology, 51(1), 148-165. https://doi.org/10.1111/bjet.12790

Cho, Y. H., Yim, S. Y., \& Paik, S. (2015). Physical and social presence in 3D virtual role-play for pre-service teachers. Internet and Higher Education, 25, 70-77. https://doi.org/10.1016/j.iheduc.2015.01.002

Cho, Y. H., \& Lim, K. Y. T. (2017). Effectiveness of collaborative learning with 3D virtual worlds. British Journal of Educational Technology, 48(1), 202-211. https://doi.org/10.1111/bjet.12356

Cuperus, A. A., Keizer, A., Evers, A. W. M., van den Houten, M. M. L., Teijink, J. A. W., \& van der Ham, I. J. M. (2018). Manipulating spatial distance in virtual reality: Effects on treadmill walking performance in patients with intermittent claudication. Computers in Human Behavior, 79, 211-216. https://doi.org/10.1016/j.chb.2017.10.037

Dalgarno, B., \& Lee, M. J. W. (2010). What are the learning affordances of 3-D virtual environments? British Journal of Educational Technology, 41(1), 10-32. https://doi.org/10.1111/j.1467-8535.2009.01038.x

Davis, F. D. (1989). Perceived usefulness, perceived ease of use, and user acceptance of information technology. MIS Quarterly, 13(3), 319-340.

De Lucia, A., Francese, R., Passero, I., \& Tortora, G. (2009). Development and evaluation of a virtual campus on Second Life: The case of SecondDMI. Computers and Education, 52(1), 220-233. https://doi.org/10.1016/j.compedu.2008.08.001

Deimann, M., \& Bastiaens, T. (2010). The role of volition in distance education: An exploration of its capacities. The International Review of Research in Open and Distributed Learning, 11(1), 1-16. https://doi.org/10.19173/irrodl.v11i1.778

Dinçer, S., \& Doğanay, A. (2016). Öğretim Materyali’ne İlişkin Motivasyon Ölçeği (ÖMMÖ) Türkçe uyarlama çalışması [Turkish adaptation study of Instructional Materials Motivation Survey (IMMS)]. Elementary Education Online, 15(4), 1131-1148. https://doi.org/10.17051/io.2016.19056

Dubovi, I., Levy, S. T., \& Dagan, E. (2017). Now I know how! The learning process of medication administration among nursing students with non-immersive desktop virtual reality simulation. Computers and Education, 113, 16-27. https://doi.org/10.1016/j.compedu.2017.05.009

Edirisingha, P., Nie, M., Pluciennik, M., \& Young, R. (2009). Socialisation for learning at a distance in a 3-D multi-user virtual environment. British Journal of Educational Technology, 40(3), 458-479. https://doi.org/10.1111/j.1467-8535.2009.00962.x

Göksu, İ., Ergün, N., Özkan, Z., \& Sakız, H. (2021). Distance education amid a pandemic: Which psycho-demographic variables affect students in higher education? Journal of Computer Assisted Learning. https://doi.org/10.1111/jcal.12544 
Guadagno, R. E., Muscanell, N. L., Okdie, B. M., Burk, N. M., \& Ward, T. B. (2011). Even in virtual environments women shop and men build: A social role perspective on Second Life. Computers in Human Behavior, 27(1), 304-308. https://doi.org/10.1016/j.chb.2010.08.008

Hair, J. F., Black, W. C., Babin, B. J., \& Anderson, R. E. (2013). Multivariate Data Analysis. Always learning. Pearson Education Limited.

Hassanein, K., \& Head, M. (2004, June 5). Instilling social presence through the web interface. Proceedings of the Third Annual Workshop on HCI Research in MIS. http://sighci.coursaris.com/wpcontent/uploads/2018/09/SIGHCI_2004_Proceedings_paper_9.pdf

Holmberg, K., \& Huvila, I. (2008). Learning together apart: Distance education in a virtual world. First Monday, 13(10). https://doi.org/10.5210/fm.v13i10.2178

Howard, M. C., \& Gutworth, M. B. (2020). A meta-analysis of virtual reality training programs for social skill development. Computers and Education, 144, 103707. https://doi.org/10.1016/j.compedu.2019.103707

Hrastinski, S. (2008a). Asynchronous and synchronous e-learning. EDUCAUSE Quarterly, 31(4), 51-55.

Hrastinski, S. (2008b). The potential of synchronous communication to enhance participation in online discussions: A case study of two e-learning courses. Information and Management, 45(7), 499-506. https://doi.org/10.1016/j.im.2008.07.005

Hrastinski, S., Keller, C., \& Carlsson, S. A. (2010). Design exemplars for synchronous elearning: A design theory approach. Computers and Education, 55(2), 652-662. https://doi.org/10.1016/j.compedu.2010.02.025

Huang, H.-M., Liaw, S.-S., \& Lai, C.-M. (2016). Exploring learner acceptance of the use of virtual reality in medical education: A case study of desktop and projection-based display systems. Interactive Learning Environments, 24(1), 3-19. https://doi.org/10.1080/10494820.2013.817436

Inoue, Y. (2012). Virtual reality learning environments. In Encyclopedia of the Sciences of Learning (pp. 3407-3410). https://doi.org/10.1007/978-1-4419-1428-6_651

Jiang, D., \& Zhang, L. J. (2020). Collaborating with 'familiar' strangers in mobile-assisted environments: The effect of socializing activities on learning EFL writing. Computers and Education, 150, 103841. https://doi.org/10.1016/j.compedu.2020.103841

Kaya, M. (2012). Distance education systems used in universities of Turkey and Northern Cyprus. Procedia-Social and Behavioral Sciences, 31, 676-680. https://doi.org/10.1016/j.sbspro.2011.12.123

Keller, J. M. (2010). Motivational design for learning and performance: The ARCS model approach. Springer US.

Ketelhut, D. J., Nelson, B. C., Clarke, J., \& Dede, C. (2010). A multi-user virtual environment for building and assessing higher order inquiry skills in science. British Journal of Educational Technology, 41(1), 56-68. https://doi.org/10.1111/j.14678535.2009.01036.x

Khan, S. (2011). Sarah \& Emma: Case studies of two instructors and how they use social presence in Second Life (Doctoral dissertation). Texas State University, TX.

Kreijns, K., Kirschner, P. A., Jochems, W., \& van Buuren, H. (2007). Measuring perceived sociability of computer-supported collaborative learning environments. Computers and Education, 49(2), 176-192. https://doi.org/10.1016/j.compedu.2005.05.004

Lall, S., \& Singh, N. (2020). COVID-19: Unmasking the new face of education. International Journal of Research in Pharmaceutical Sciences, 11(Special Issue 1), 48-53. https://doi.org/10.26452/ijrps.v11iSPL1.2122 
Lee, I. S. (2002). Gender differences in self-regulated online learning strategies within Korea's university context. Educational Technology Research and Development, 50(1), 101111. https://doi.org/10.1007/BF02504967

Li, C., \& Lalani, F. (2020, Apr 29). The COVID-19 pandemic has changed education forever. This is how. World Economic Forum. https://www.weforum.org/agenda/2020/04/coronavirus-education-global-covid19online-digital-learning/

Liou, H. C. (2012). The roles of Second Life in a college computer-assisted language learning (CALL) course in Taiwan, ROC. Computer Assisted Language Learning, 25(4), 365382. https://doi.org/10.1080/09588221.2011.597766

Liu, O. L. (2012). Student evaluation of instruction: In the new paradigm of distance education. Research in Higher Education, 53(4), 471-486. https://doi.org/10.1007/s11162-0119236-1

McMillan, J. H., \& Schumacher, S. (2010). Research in education: Evidence-based inquiry (7th ed.). London: Pearson.

Merchant, Z., Goetz, E. T., Cifuentes, L., Keeney-Kennicutt, W., \& Davis, T. J. (2014). Effectiveness of virtual reality-based instruction on students' learning outcomes in K12 and higher education: A meta-analysis. Computers and Education, 70, 29-40. https://doi.org/10.1016/j.compedu.2013.07.033

Meşe, E., \& Sevilen, Ç. (2021). Factors influencing EFL students' motivation in online learning: A qualitative case study. Journal of Educational Technology \& Online Learning, 4(1), 11-22. https://doi.org/10.31681/jetol.817680

Mikropoulos, T. A., \& Bellou, J. (2006). The unique features of educational virtual environments. In P. Isaías, M. McPherson, \& F. Bannister (Eds.), Proceedings e-society 2006 (pp. 122-128). International Association for Development of the Information Society.

Milićević, V., Denić, N., Milićević, Z., Arsić, L., Spasić-Stojković, M., Petković, D., Stojanović, J., Krkic, M., Milovančević, N. S., \& Jovanović, A. (2021). E-learning perspectives in higher education institutions. Technological Forecasting and Social Change, 166, 120618. https://doi.org/10.1016/j.techfore.2021.120618

Minocha, S., \& Reeves, A. J. (2010). design of learning spaces in 3D virtual worlds: an empirical investigation of Second Life. Learning, Media and Technology, 35(2), 111137. https://doi.org/10.1080/17439884.2010.494419

Mockus, L., Dawson, H., Edel-Malizia, S., Shaffer, D., An, J., \& Swaggerty, A. (2011). The impact of mobile access on motivation: Distance education student perceptions. World Campus Learning Design, 4(5), 1-34.

Morozov, M., Gerasimov, A., \& Fominykh, M. (2012). vAcademia-Educational Virtual World with 3D recording. In 2012 International Conference on Cyberworlds (pp. 199-206). IEEE.

Ozonur, M., Yanpar-Yelken, T., \& Sancar-Tokmak, H. (2018). Social presence and motivation in online environments: Second Life versus the Enocta Learning Management System/Adobe Connect. Australasian Journal of Educational Technology, 34(3), 1-14. https://doi.org/10.14742/ajet.3128

Perbandt, D., Heinelt, M. S., Bacelar-Nicolau, P., Mapar, M., \& Caeiro, S. S. (2021). Towards effective e-learning on sustainability: a case study-course on participatory processes in environmental politics. International Journal of Sustainability in Higher Education. https://doi.org/10.1108/IJSHE-07-2020-0262

Ploj Virtic, M., Dolenc, K., \& Šorgo, A. (2021). Changes in online distance learning behaviour of university students during the Coronavirus Disease 2019 Outbreak, and development 
of the model of forced distance online learning preferences. European Journal of Educational Research, 10(1), 393-411. https://doi.org/10.12973/eu-jer.10.1.393

Pojanapunya, P., \& Jaroenkitboworn, K. (2011). How to say "Good-bye" in Second Life. Journal of Pragmatics, 43(14), 3591-3602. https://doi.org/10.1016/j.pragma.2011.08.010

Prasolova-Førland, E., Fominykh, M., \& Leong, P. (2013). 3D recording as enabling technology for serious games and educational roleplaying. In Proceedings of the ACM SIGGRAPH Symposium on Interactive 3D Graphics and Games (pp. 177-177). ACM.

Research and Markets. (2020, August 15). Distance Learning - Global Market Outlook (20182027). https://www.researchandmarkets.com/reports/5017511/distance-learningglobal-market-outlook-2018

Rogers, E. (2003). Diffusion of innovation. Free Press.

Rovai, A., Ponton, M., Wighting, M., \& Baker, J. (2007). A comparative analysis of student motivation in traditional classroom and e-learning courses. International Journal on ELearning, 6(3), 413-432.

Salmon, G. (2004). E-moderating: the key to teaching and learning online (2nd ed.). Routledge. Salmon, G. (2009). The future for (second) life and learning. British Journal of Educational Technology, 40(3), 526-538. https://doi.org/10.1111/j.1467-8535.2009.00967.x

Saxena, C., Baber, H., \& Kumar, P. (2021). Examining the moderating effect of perceived benefits of maintaining social distance on e-learning quality during Covid-19 pandemic. Journal of Educational Technology Systems, 49(4), 532-554. https://doi.org/10.1177/0047239520977798

Sindiani, A. M., Obeidat, N., Alshdaifat, E., Elsalem, L., Alwani, M. M., Rawashdeh, H., Fares, A. S., Alalawne, T. \& Tawalbeh, L. I. (2020). Distance education during the COVID19 outbreak: A cross-sectional study among medical students in North of Jordan. Annals of Medicine and Surgery, 59, 186-194. https://doi.org/10.1016/j.amsu.2020.09.036

Stein, D. S., Wanstreet, C. E., Glazer, H. R., Engle, C. L., Harris, R. A., Johnston, S. M., ... Trinko, L. A. (2007). Creating shared understanding through chats in a community of inquiry. Internet and Higher Education, 10(2), 103-115. https://doi.org/10.1016/j.iheduc.2007.02.002

Tang, Y. M., Chen, P. C., Law, K. M., Wu, C. H., Lau, Y. Y., Guan, J., ... \& Ho, G. T. (2021). Comparative analysis of Student's live online learning readiness during the coronavirus (COVID-19) pandemic in the higher education sector. Computers \& Education, 168, 104211.

Tüzün, H., Yilmaz-Soylu, M., Karakuş, T., Inal, Y., \& Kizilkaya, G. (2009). The effects of computer games on primary school students' achievement and motivation in geography learning. Computers and Education, 52(1), 68-77. https://doi.org/10.1016/j.compedu.2008.06.008

Usluel, Y. K., \& Mazman, S. G. (2010). Eğitimde yeniliklerin yayılımı, kabulü ve benimsenmesi sürecinde yer alan öğeler: Bir içerik analizi çalışması [Elements involved in the diffusion, acceptance and adoption of innovations in education: A content analysis study]. Cukurova University Faculty of Education Journal, 3(39), 69-74.

Xie, K., \& Ke, F. (2011). The role of students' motivation in peer-moderated asynchronous online discussions. British Journal of Educational Technology, 42(6), 916-930. https://doi.org/10.1111/j.1467-8535.2010.01140.x

vAcademia. (2020, July 10). vAcademia Platform. http://vacademia.com/

Yamada, M. (2009). The role of social presence in learner-centered communicative language learning using synchronous computer-mediated communication: Experimental study. Computers and 8ducation, 820-833. https://doi.org/10.1016/j.compedu.2008.12.007 
Yao, S., Li, D., Yohannes, A., \& Song, H. (2021). Exploration for network distance teaching and resource sharing system for higher education in epidemic situation of COVID-19. Procedia Computer Science, 183, 807-813. https://doi.org/10.1016/j.procs.2021.03.002

Yawson, D. E., \& Yamoah, F. A. (2021). Gender variability in E-learning utility essentials: Evidence from a multi-generational higher education cohort. Computers in Human Behavior, 114, 106558. https://doi.org/10.1016/j.chb.2020.106558

Yee, N. (2006). Motivations for play in online games. Cyberpsychology and Behavior, 9(6), 772-775. https://doi.org/10.1089/cpb.2006.9.772

Yilmaz, R., Aydemir, M., Karaman, S., \& Goktas, Y. (2016). Social presence in a Three Dimensional Virtual World used for distance education. Croatian Journal of Education, 18(3), 859-897. https://doi.org/10.15516/cje.v18i3.1664

Zhang, Y., Dang, Y., \& Chen, H. (2013). Research note: Examining gender emotional differences in web forum communication. Decision Support Systems, 55, 851-860. https://doi.org/10.1016/j.dss.2013.04.003

Zhou, Z., Jin, X. L., Vogel, D. R., Fang, Y., \& Chen, X. (2011). Individual motivations and demographic differences in social virtual world uses: An exploratory investigation in Second Life. International Journal of Information Management, 31(3), 261-271. https://doi.org/10.1016/j.ijinfomgt.2010.07.007 